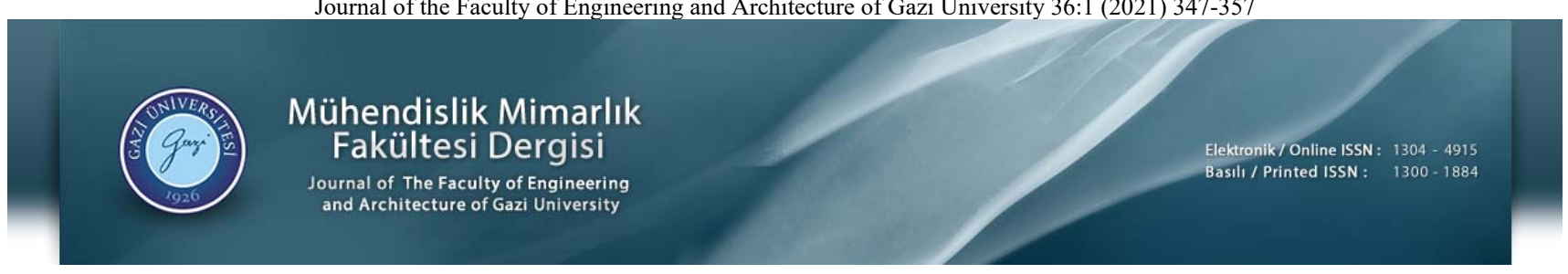

\title{
A convolutional neural network model for marble quality classification
}

\author{
İdris Karaali (iD, Mete Eminağaoğlu*(i) \\ Department of Computer Science, Dokuz Eylül University, İzmir, 35390, Turkey
}

\section{Highlights:}

- Use of convolutional neural networks for multi-classification

- Marble quality classification with slab images

- Data augmentation with image processing filters

\section{Keywords:}

- Convolutional neural networks

- Marble images

- Data augmentation

- Marble quality classification

- Machine learning

\section{Article Info:}

Research Article

Received: 14.04.2020

Accepted: 17.08.2020

DOI:

10.17341/gazimmfd.720041

\section{Correspondence:}

Author: Mete Eminağaoğlu e-mail: mete.eminagaoglu @deu.edu.tr phone: +90 5339687979

\section{Graphical/Tabular Abstract}

IMarble quality classification by human experts can be time-consuming, error-prone, unreliable, and subjective. Automated and computerized methods are needed to obtain more reliable, faster, and less subjective results. In this study, a deep learning model is developed in order to perform multi-classification of marble slab images with six different quality types. Some special image pre-processing operations were applied to the images for data augmentation and a special convolutional neural network (CNN) architecture was designed and implemented. It has been observed that the data augmentation approach for marble image samples has significantly improved the accuracy of the CNN model.

Table A. Performance comparison using the augmented dataset with 6300 images

\begin{tabular}{llll}
\hline Classifier & $\begin{array}{l}\text { Accuracy } \\
\text { (Train) }\end{array}$ & $\begin{array}{l}\text { Accuracy } \\
\text { (Test) }\end{array}$ & $\begin{array}{l}\text { Accuracy } \\
\text { (10-folds } \\
\text { x-val.) }\end{array}$ \\
\hline Our CNN model & 1.000 & 0.922 & 0.961 \\
k-NN (k=1) & 0.906 & 0.729 & 0.703 \\
Multilayer Perceptron (hidden layer: 64 nodes) & 0.893 & 0.748 & 0.757 \\
Multilayer Perceptron (hidden layers: 256 and & 0.917 & 0.705 & 0.712 \\
128 nodes) & 0.821 & 0.694 & 0.685 \\
C4.5 Decision Tree & 0.735 & 0.655 & 0.661 \\
Naïve Bayes & & & \\
\hline
\end{tabular}

Purpose: This study aims to propose a novel marble quality classification model that could provide accuracy scores at least as good as human experts, which might be implemented and used in the marble industry as autonomous agents that could minimize human intervention and human workforce requirements in the near future. To the best of our knowledge, the use of CNN for marble quality multi-classification and image preprocessing and data augmentation techniques for marble quality classification is known to be a novel approach and model in the related literature.

\section{Theory and Methods:}

The original dataset consisted of 2100 marble images with six different classes. Image blurring was achieved by convolving the image with a low-pass filter $4 \times 4$ kernel. After that, 2D linear separable filter was applied. After these data augmentation operations, the marble image dataset size was increased up to 6300. Batch normalization was used for the input data with a batch size of 16 within CNN. Two convolution layers with 64 and 128 filters of (3x3) sizes were used. A fully connected layer was used where 139392 nodes were fully connected with 512 nodes and a dropout rate of 0.50 . CNN model was trained for 30 epochs and Adam is used with an initial learning rate of 0.001 .

\section{Results:}

The average accuracy scores obtained by our CNN model using the augmented dataset with 6100 images were 0.922 (test) and 0.961 (ten-folds cross-validation), which are both much higher than the results obtained by other algorithms. In addition, these results are considered to be at least as good as (or even exceeding) the human experts' manual classification. The novelty of our study and its contributions can be summarized as follows; the use of a specifically designed convolutional neural network for marble quality classification, the use of specific two image processing methods (Blur filter and 2D linear separable filter) for data augmentation, the delivery of highly successful results without overfitting problems.

\section{Conclusion:}

It can be concluded that this CNN and data augmentation model can be implemented and used in marble companies as a fully automated and computerized alternative for manual operations carried out by humans 


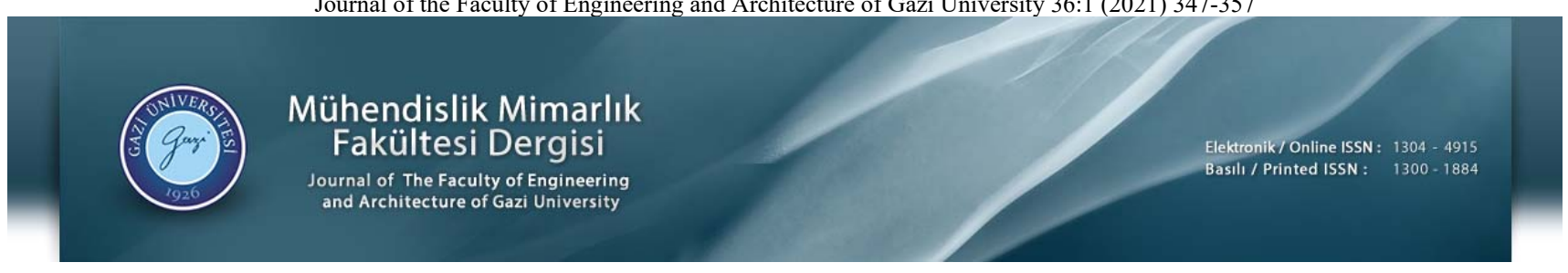

\section{Mermer işlemede kalite sınıflandırması için evrişimsel sinir ağı modeli}

İdris Karaali(i), Mete Eminağaoğlu*(i)

Dokuz Eylül Üniversitesi, Fen Fakültesi, Bilgisayar Bilimleri Bölümü, 35390 Buca İzmir

\section{Ö N E Ç I K A N L A R}

- Evrişimsel sinir ağları ile çoklu sınıflandırma

- Mermer levhalarının resimleri ile kalite sınıflandırması

- Görüntü işleme filtreleri ile veri artırımı

Makale Bilgileri

Araştırma Makalesi

Geliș: 14.04 .2020

Kabul: 17.08.2020

DOI:

10.17341/gazimmfd.720041

Anahtar Kelimeler:

Evrişimsel sinir ağları, mermer resimleri, veri artırımı, mermer kalitesi sinıflandırması, yapay öğrenme

\section{ÖZET}

Mermer işletmelerinin temel politikası; sürdürülebilir ve yüksek kaliteli ürünleri standartlaşmış bir yöntemle ortaya koymaktır. Farklı türdeki mermerlerin tanımlanması ve sınıflandırılması, genellikle bu alandaki uzman kişiler tarafindan manuel olarak gerçekleştirilen kritik bir iştir. Bununla birlikte; mermer kalitesi sınıflandırılmasının insanlar tarafından ve manuel şekilde yapılması oldukça zaman alıcı, hatalara fazlasıyla açık, aynı zamanda da güvenilir olmayan ve öznel bir süreçtir. Bu süreci daha nesnel ve güvenilir, çok daha hızlı ve çok daha az insan müdahalesi gerektirecek şekilde otomatik hale dönüştüren bilgi teknolojilerine dayalı yaklaşımlar ve yöntemlere büyük ölçüde gereksinim vardır. Bu çalışmada; levha mermer resimlerini işleyerek altı farklı kalite tipine göre sınıflandıran bir derin öğrenme modeli geliştirilmiştir. Veri artırımı amacıyla, orijinal mermer resimlerine özgü bir görüntü ön işleme süreci gerçekleştirilmiş ve özel bir evrişimsel sinir ağı mimarisi tasarlanıp uyarlanmıştır. Mermer görselleri üzerinde bu çalışmada uygulanan özgün veri artırımı yaklaşımının, evrişimsel sinir ağı modelinin sınıflandırma başarısı ve doğruluk değerlerini çok önemli düzeyde arttırdığı gözlenmiştir. Evrişimsel sinir ağı modeli ile alternatif yapay öğrenme algoritmalarının tamamından çok daha başarılı sonuçlar elde edildiği ve mermer işlemedeki kalite kontrol uzmanlarının performanslarına yakın başarı düzeyinde sınıflandırma yapılabildiği ortaya konulmuştur.

\section{A convolutional neural network model for marble quality classification}

\section{H I G H L I G H T S}

- Use of convolutional neural networks for multi-classification

- Marble quality classification with slab images

- Data augmentation with image processing filters

\section{Article Info}

Research Article

Received: 14.04 .2020

Accepted: 17.08.2020

DOI:

10.17341/gazimmfd.720041

\section{Keywords:}

Convolutional neural networks, marble images,

data augmentation, marble quality classification, machine learning

\section{ABSTRACT}

The basic policy of marble enterprises is to establish sustainable high-quality products in a standardized manner. Identification and classification of different types of marbles is a critical task that is usually carried out by human experts. However, marble quality classification by human experts can be time-consuming, errorprone, unreliable, and subjective. Automated and computerized methods are needed to obtain more reliable, faster, and less subjective results. In this study, a deep learning model is developed in order to perform multiclassification of marble slab images with six different quality types. Some special image pre-processing operations were applied to the images for data augmentation and a special convolutional neural network (CNN) architecture was designed and implemented. It has been observed that the data augmentation approach for marble image samples has significantly improved the accuracy of the CNN model. We have obtained outstanding results with our CNN model, which surpassed the alternative machine learning algorithms and even equalized the human experts' classification performance.

\footnotetext{
"Sorumlu Yazar/Corresponding Author: karaaliidris@gmail.com, mete.eminagaoglu@deu.edu.tr / Tel +90 533968797 


\section{GIRIŞS (INTRODUCTION)}

Sert taşlar ve kayalar haricinde; renk, doku ve yapı taşı özellikleri açısından homojen olan mermerlere ve mermer kayaçlarına yeryüzünde pek rastlanmamaktadır. Süreksizlikler, renk farkları, yabancı parçacıkların ya da öğelerin varlığı, blok şekiller ve çeşitli ölçümler; mermerin niteliğini etkileyen ana faktörlerdir. Mermer blokları; mermer tipinin genel özelliklerine, içsel parametrelerine, mermer ocağının jeolojik karakteristiklerine, işleme hattı ve kullanım karakteristiklerine göre değerlendirilir [1]. Günümüzde mermerlerin kalitelerine göre sınıflandırılması; donanım ve yazılım teknolojilerindeki ilerlemelere karşın çoğunlukla insan iş gücü ve uzman kişilerin müdahalesiyle gerçekleştirilmektedir.

Bir mermerin kalitesi genellikle; o mermerin üzerindeki fosiller ve lekeler kadar, mermerin yoğunluğuna ve büyüklüğüne bağlı olarak değişebilmektedir [1]. Bir literatür çalışmasında, mermer kalitesinin sınıflandırılmasına ilişskin çeşitli klasik yaklaşımlar veya yöntemler ortaya konulmuştur [2]. İlgili çalışmaların çoğunda mermer levhalarının fotoğraflarının kalite siniflandırma sistemlerine dâhil edilmeden önce; Gabor, yüzdelik gibi farklı filtrelerle ya da kromatik özelliklerinin çıkartılması gibi diğer tekniklerle görüntü ön-işleme sürecinden geçirildiği bilinmektedir [3]. İlgili çalışmada, renkli granit karolarının resimlerinden oluşan toplam 12 farklı kalite sınıfı ve her bir sınıftan 48 adet örneği içerecek şekilde toplam 576 örnekten oluşan bir veri kümesi kullanılmıştır [3]. Granit görsellerindeki bozunum (distortion) etkisini en aza indirgemek adına, 1500 x 1500 piksel boyutlarındaki görseller kırpılma işlemiyle 544 x 544 boyutuna küçültülmüştür. Destek Vektör Makinesi (Support Vector Machine) algoritması kullanılarak \% 98,5' lik bir doğruluk oranı elde edilmiştir [3].

Mermer görsellerine bağlı olarak yapılan kalite sınıflandırmasına ilişkin literatürde yer alan diğer bir çalışmada ise K-ortalamalar kümeleme (K-means clustering) algoritması kullanılarak mermer sınıflandırması için endüstriyel bir uygulama geliştirilmiştir [4]. Bu çalışmada, mermerlerin görsellerine ait resim büyüklükleri 315 x 310 piksel olacak şekilde ayarlanmıştır. Her bir farklı mermer kalitesi sınıfı için örneklem adetleri sırasıyla 172, 388, 411 ve 187 olarak alınmış ve toplamda 1158 örnekten oluşan bir veri kümesi kullanılmıştır [4]. Toplam ve fark histogramları (SDH) [5] kullanılarak elde edilen ve ayrıca; ortalama, varyans, enerji, korelasyon, entropi, kontrast ve homojenlik özelliklerinin hesaplanmasında kullanılan dokusal özellikler mermer sınıflandırmasına dâhil edilmiştir [6]. Diğer yandan, bir örneklemin enerji ayrışmasını sağlayan dalgacık dönüşümü tabanlı (wavelet transform-based) özellikler elde edilmiş [7] ve bu özellikler ayrışmanın her bir düzeyinin ortalama, medyan ve varyansını hesaplamada kullanılmıştır. K-ortalamalar kümeleme algoritması kullanılarak \% 83,60’lık bir doğruluk (accuracy) elde edilmiştir [4].

Doğan ve Akay; dört farklı mermer kalitesine ait mermer fotoğraflarını içeren bir görsel veri seti kullanarak yaptıkları çalışmada yüksek düzeyde doğruluk oranları elde etmiştir [8]. Toplam ve fark histogramları ile AdaBoost algoritmasını kullanarak, mermer levhalarının otomatik olarak sınıflandırmasını yapan bir sistem ortaya koymuşlardır. Dört farklı kalite sınıfına ait, toplamda 1158 örnekten oluşan bir veri kümesi kullanılmış ve AdaBoost algoritması ile her bir farklı mermer kalite sınıfı için doğruluk oranları sırasıyla \% 96,52, \% 91,79, \% 94,53 ve \% 99,25 olarak elde edilmiştir [8]. Araştırmacıların diğer bir çalışmasında da aynı veri kümesinde Hiyerarşik Radyal Temelli Fonksiyon Ağ1 (Hierarchical Radial Basis Function Network) kullanılarak oldukça yüksek doğruluk oranlarında sonuçlar elde edilmiştir [9].

Ferreria ve Giraldi; granit karolarının sınıflandırılmasında Evrişimsel Sinir Ağlarını (Convolutional Neural Networks) kullanan bir yöntem önermiştir [10]. Evrişimsel sinir ağ1 içinde yer alan eğitim verilerinde $28 \times 28$ piksel boyutundaki siyah-beyaz görseller ve 32 x 32 'lik renkli görseller kullanmışlardır. Bu veri setleri, aynı zamanda Bianconi ve arkadaşlarının çalışmasında da [11] kullanılmış olan granit karolarının resimlerinin görüntü işleme ile küçültülmüş türevleridir. $\mathrm{Bu}$ çalışmalardaki orijinal granit karo verileri ise; $1500 \times 1500$ piksel boyutunda, 25 farklı sinifa ait ve her sınıfta 40 adet granit fotoğrafinın yer aldığı, toplam 1000 adet renkli görseli içermektedir. İlk 100 görsel örneği, bir görüntü işleme sistemi ile taranarak elde edilmiştir. Kalan 900 örnek ise; orijinal görsellerin 10 ile 90 derece arasında dokuz farklı açıyla döndürülmesiyle elde edilmiştir [10]. Bu görseller; toplam 2809000 örnekten oluşmakta olup, MNIST verileri [12] için önceden eğitilmiş (pre-trained) bir evrişimsel sinir ağında kullanılmak üzere, 28 x 28 piksel ebatlarında siyah beyaz görsellere dönüştürülmüştür. Benzer şekilde ayrıca; CIFAR verileriyle [13] önceden eğitilmiş bir evrişimsel sinir ağında çalıştırılmak üzere 2116000 adet 32 x 32 boyutlarında renkli görseller hazırlanmıştır. Sınıflandırmadaki başarım ölçümü için 5 x 2 'lik çaprazgeçerleme yöntemi kullanılmıştır. Evrişimsel sinir ağındaki eğitim sürecinde; öğrenme hız 0,001 değerinde sabit tutulmuş ve momentum değeri de 0,9 olarak ayarlanmıştır. Ağdaki hataların geri yayılımı ve ağırlıkların güncellenmesinde stokastik kademeli azalma (stochastic gradient descent) yöntemi kullanılmış ve ağırlıklardaki azalım hızı (decay rate) 0,0005 olarak belirlenmiştir. Araştırmacılar ayrıca, önceden eğitilmiş CIFAR modeli ile renkli karoların eğitimi sürecinde de benzer parametreleri kullanmıştır; ancak bu süreçteki tek farklılık, ağırlıklardaki azalım hızının 0,0001 olarak kullanılması olmuştur. Renkli karo görsellerinde \% 87,26' lik bir doğruluk oranı elde edilmiştir.

Yakın zamanda yapılmış olan bir çalışmada ise, mermer levha görsellerinin sınıflandırılmasında evrişimsel sinir ağları kullanılmıştır [14]. Pençe ve Çeşmeli' nin bu çalışmasında, 80 farklı mermer görseli üzerinde çeşitli evrişimsel sinir ağı mimarileri ve farklı hiper-parametreler kullanılarak deneyler yapılmıştır [14]. Bununla birlikte; bu çalışmada veri artırımı için hiçbir yöntem kullanılmamıştır. Ayrıca, mermer görsellerinin kalitesine göre ayırt edilmesi 
kapsamında sadece ikili sınıflandırma tercih edilmiştir ki, endüstriyel uygulamalarda mermerlerin ikiden daha fazla kalite düzeyine ayrıştırılması gerekmektedir. Çalışmada elde edilen en yüksek doğruluk oranının \% 75 civarı olduğu belirtilmiştir.

Bu çalışmada; mermer endüstrisinde yakın gelecekte insan müdahalesini ve insan iş gücü gerekliliklerini minimize edebilecek şekilde, en az mermer eksperlerinin ortaya koyduğu düzeyde doğru sınıflandırmayı, çok hızlı ve etkin bir şekilde, otomatikleştirilmiş olarak yapabilecek yeni bir mermer sınıflandırması modeli ortaya konulmuştur. Bugüne kadar literatürdeki bilinen tüm çalışmalardan farklı olarak; mermer kalitesinin çoklu sınıflandırmasında evrişimsel sinir ağlarının bu düzeyde başarılı sonuç vermesi ve evrişimsel sinir ağlarının doğruluk oranını, aşırı uyumu (overfitting) da engelleyecek şekilde arttıran bazı veri artırım (data augmentation) tekniklerinin özgün bir biçimde kullanımı, bu çalışmanın önemini ortaya koyan yeni bir yaklaşımdır.

\section{MALZEMELER VE YÖNTEMLER (MATERIALS AND METHODS)}

Bu çalışmada kullanılan mermer levhalarının görselleri, İzmir'de kurulmuş uluslararası bir şirket olan Haz Mermer Sanayi ve Ticaret A. Ş.' den sağlanan gerçek ürünlere aittir. Her bir kalite sınıfı için örnek sayısı 350 adet renkli fotoğraftır ve toplamda 2100 örnekten oluşan bir veri setini oluşturmaktadır. Bu görsellerin özgün boyutları 2400 x 2400 piksel büyüklüğündedir. Veri setindeki tüm görseller kırpılmıştır ve bu sayede nihai veri seti, 300 x 300 piksel boyutundaki renkli (RGB) mermer levha fotoğraflarından oluşmuştur. Toplam altı farklı kalite kategorisinden oluşan bu mermer levhalar Q3-A, Q3-B, Q3-C, Q4-A, Q4-B, Q4-C şeklinde etiketlenmiştir. $\mathrm{Bu}$ farklı kalitedeki sınıfların bazılarından alınan örnek görseller, fikir vermesi açısından Şekil 1'de ve Şekil 2'de gösterilmektedir.

Farklı sınıflara ait olan mermer örneklerinin çoğunluğunun görüntü olarak birbirine çok benzer olmasından ve bir mermer kalite eksperi tarafindan bile bazen ayırt edilmesinin çok güç olmasından dolayı, mermerlerin kalitelerine göre ayrıştırılmasının son derece zor bir iş olduğunun altı çizilmelidir. Buna ek olarak; bazı mermer örnekleri, aynı kalite sınıfına ait olmalarına rağmen, yüzeylerindeki renklerden ve bazı desenlerden ya da damarlardan ötürü pek çok insanın görsel algısına göre tamamıla farklı görünebilmektedir. Diğer bir deyişle, mermer örneklerinin hem yanlış pozitif (false positive) hem de yanlış negatif (false negative) şekilde kategorize edilme riski son derece yüksek düzeyde olabilmektedir. Bu çalışmada kullanılan mermer görselleri ve verileri için de bu sorunlar ve güçlükler benzer şekilde geçerlidir. Örneğin, Şekil 3a, Şekil $3 b$ ve Şekil 3c'de de görülebileceği gibi, hem insan hem de bilgisayar görsel görüşü için aynı sınıftaki bu mermer görsellerini algılamak ve doğru sinıflara atamak son derece zor bir iştir.

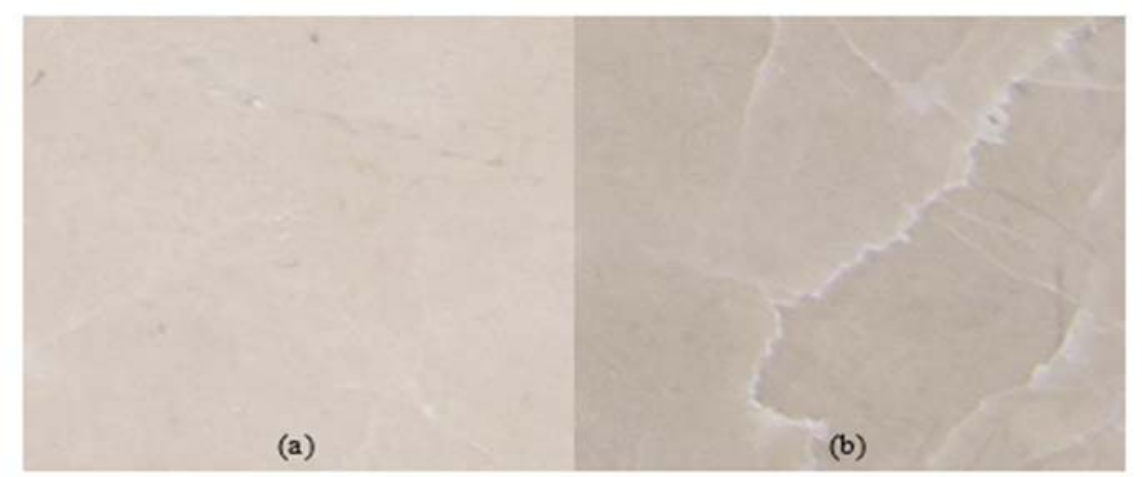

Şekil 1. İki farklı kalite sınıfına ait mermer levha örnekleri (Marble slab images from two different quality classes) (a) Q3-B sinıfı (quality class: Q3-B), (b) Q3-C sinıfi (quality class: Q3-C)

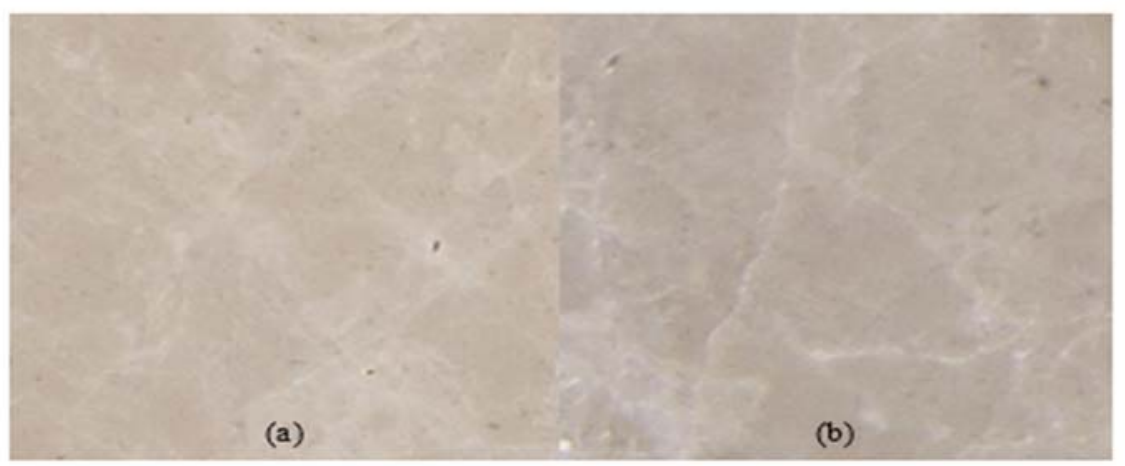

Şekil 2. İki farklı kalite sınıfına ait mermer levha örnekleri (Marble slab images from two different quality classes) (a) Q4-A sinıfi (quality class: Q4-A), (b) Q4-B sinıfi (quality class: Q4-B) 


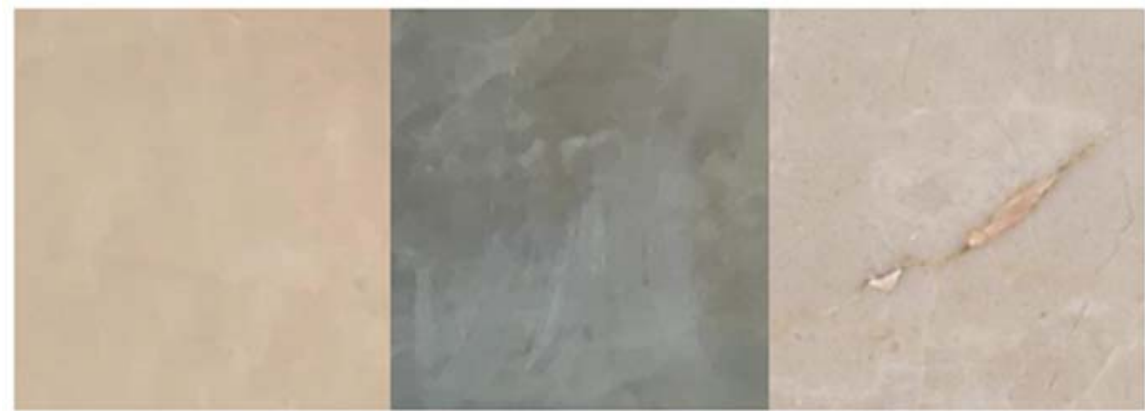

Şekil 3. Q4-C kalite sınıfina ait üç adet mermer levha görseli (Three marble slab images from Q4-C quality class)

$\mathrm{Bu}$ çalışmada kullanılan evrişimsel sinir ă̆ı, son yıllarda oldukça yaygınlaşan ve birçok alanda çok başarılı sonuçlar veren derin öğrenmedeki en çok bilinen mimari ve yapılardan birisidir. Derin öğrenme kavramı, çeşitli kaynaklarda farklı biçimlerde tanımlansa da; en basit şekliyle, yapay sinir ağlarının çok sayıda gizli katman içeren, daha karmaşık öğrenme yöntemleri ve çok daha fazla sayıda değişken, parametre ve hesaplama işlemleriyle ele alındığı, dolayısıyla yüksek kapasitede bellek ve işlemci gerektiren yapay öğrenme modeli olarak tanımlanabilir [15]. Günümüzde çok katmanlı algılayıcı (multilayer perceptron) gibi klasik yapay sinir ağları ya da diğer yapay öğrenme algoritmalarıyla çözülemeyen ya da yeterince başarılı sonuç elde edilemeyen birçok problem, derin ögrenme ile artık çözüme ulaştırılmaktadır $[16,17]$.

Evrişimsel sinir ağları; ağırlıklı olarak görsel veriler ve görüntü işleme ya da çoklu sınıflandırma kapsamındaki çeşitli zor işlerde çok başarılı sonuçlar alınabilen bir derin öğrenme türüdür. Evrişimsel sinir ağları ilk olarak ızgara benzeri topolojik verilerin (görüntüler ve zaman serisi verileri) işlenmesi amacıyla yapılan bir çalışmada ortaya konulmuştur [18]. Evrişimsel sinir ağları; görüntü ön-işleme ve görsel verilerin hesaplanmasında yaşanan aşırı sayıda işlemi ve işlem karmaşıklığını daha farklı ve daha verimli bir şekilde ele almak için tasarlanmıştır [19, 20]. Fotoğraf, video, vb. görsel verilerden yeni öznitelikler ve desenler çıkartılması ve verilerin sınıflandırılması işlemlerinde günümüzde bilinen en başarılı, verimli ve esnek modeldir. Evrişimsel sinir ağlarının çalışması sürecinde dört ana aşama bulunmaktadır. Birinci aşama olan evrişim sürecinde, çeşitli görüntü filtreleri ile girdi verilerinden öznitelik haritaları ve örüntüleri elde edilmektedir. Pooling aşamasında, bir görselin örüntüsünün alt kümesinin elde edilerek görselin farklı türevlerinin de evrişimsel sinir ağı tarafindan doğru şekilde tanınmasını sağlar. Düzleştirme (flattening) aşamasında, çok boyutlu öznitelik kümesinin tek boyutlu bir dizin şekline dönüştürülmesi ve böylece son aşamadaki tam bağlantılı (fully connected) katmanlara girdi olarak iletimi sağlanır. Son aşamada da, çok katmanlı algılayıcıya benzer şekilde, bir ya da birkaç adet gizli katmandan oluşan tam bağlantılı katmanlarda verilerin sınıflandırılması ve oluşan hataların geri yayılımla hesaplanıp ağırlıkların güncellenmesi yapılır $[15,16]$.

Evrişimsel sinir ağlarında; evrişim katmanları ve tam bağlantılı katmanların gizli ara katmanlarında çıktı aktivasyon fonksiyonu olarak genelde ReLU (Rectified Linear Unit) kullanılmaktadır [15, 16]. ReLU aktivasyon fonksiyonu ilk olarak dinamik bir ağ modelinde ortaya konulmuştur [21]. ReLU; doğrusal olmaması, çok basit ve çok hızlı çalıştırılabilmesi ve birinci dereceden türevinin de kendi cinsinden ifade edilebilmesi nedeniyle, derin öğrenme modellerinde ve özellikle evrişimsel sinir ağlarında en çok kullanılan aktivasyon fonksiyonudur. Bir düğüme girdi olarak gelen değer $x$ olarak ifade edilirse, ReLU aktivasyon fonksiyonu $F(x)=$ maksimum $(0, x)$ olarak tanımlanabilir.

Softmax fonksiyonu, sınıfları tahmin etmek için modelin son katmanında kullanılmakta olup evrişimsel sinir ağlarında da, özellikle çoklu sınıflandırma işlemlerinde sıkça tercih edilmektedir. Softmax fonksiyonunun çıtıtı değerleri $[0,1]$ aralığında olup birinci dereceden türevinin de kendisi cinsinden ifade edilebilmesi nedeniyle hataların geri yayılımı gibi işlemlerde de oldukça kullanışlı bir fonksiyondur $[16,20]$. Softmax fonksiyonu Eş. 1'de tanımlanmış olup herhangi bir $j$ girdi değerine ait $S_{j}$ çıktı değeri, denklemdeki gibi hesaplanmaktadır.

$S_{j}=\frac{e^{a_{j}}}{\sum_{k=1}^{N} e^{a_{k}}}$

\section{TASARIM VE UYGULAMA (DESIGN AND IMPLEMENTATION)}

$\mathrm{Bu}$ çalışmada kullanılan evrişimsel sinir ağı modelimizin mimari tasarımı ve yapısı, Şekil 4'te gösterilmiştir. Birçok farklı evrişimsel sinir ağ 1 modeli ve çok farklı hiperparametrelerle deneyler yapılmış ve en başarılı sonuçların bu mimari ile elde edildiği gözlemlenmiştir. Girdi katmanında, yığın normalleştirmesi (batch normalization) kullanılmıştır. Bir sonraki aşamada; her bir görsel, iki evrişim katmanından (convolution layer) geçirilmekte ve sırasıyla 64 ve 128 adet (3 x 3) filtreler bu katmanlarda kullanılmaktadır. Her bir evrişim katmanında, çıktı aktivasyon fonksiyonu olarak ReLU kullanılmaktadır. İkinci evrişim katmanındaki ReLU işlemlerinde, 0,20 oranında bir seyreltme (dropout) kullanılmıştır. $\mathrm{Bu}$ çalışmadaki evrişimsel sinir ağ modelimizde; bilinen birçok evrişimsel sinir ağ1 mimari ve modelinin aksine, max pooling ya da average pooling işlemi hiç bir aşamada kullanılmamıştır. Bunun nedeni de, pooling mekanizmasının modelimize eklendiği durumlarda, altı 

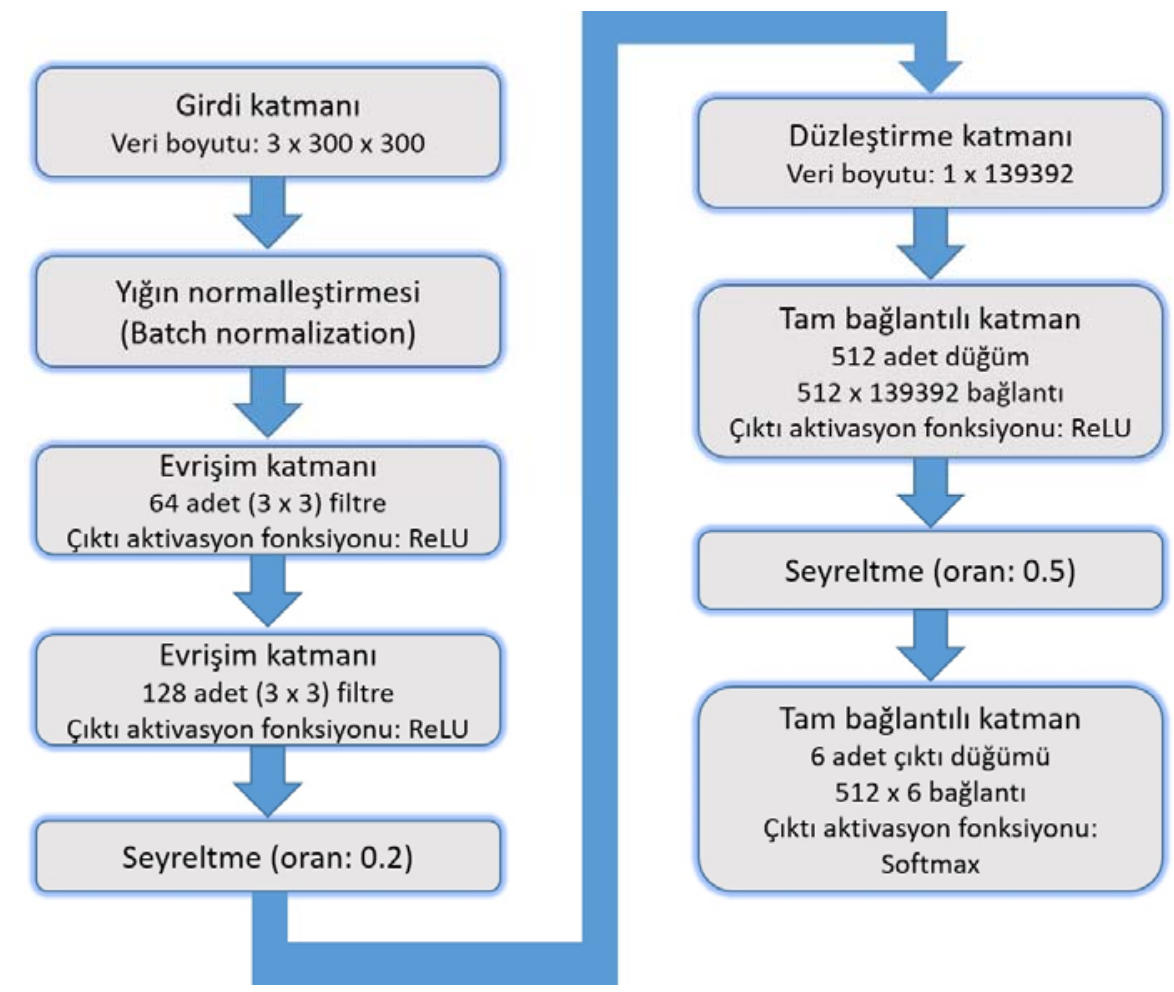

Şekil 4. Evrişimsel sinir ağımızın mimari yapısı (Architecture of our convolutional neural network model)

sınıftan özellikle ikisine ait verilerin sınıflandırmasında doğruluk oranlarında ciddi düşüşler gözlenmiş olmasıdır. Evrişimsel sinir ağı modelimizin bir sonraki aşamasında; verinin 139392 elemanlı tek boyutlu bir dizine dönüştürülmesi için bir düzleştirme katmanı (flattening layer) kullanılmıștır. Bu tek boyutlu dizin, tam bağlantılı katmanın 139392 düğümden oluşan girdi katmanı olarak kullanılmış ve 512 adet düğümden oluşan bir gizli katmana bağlanmıştır. Tam bağlantılı katmanda 0,50 oranında bir seyreltme de kullanılmıştır ve çıktı aktivasyon fonksiyonu olarak ReLU kullanılmıştır. Son aşamada da, 512 adet düğüm, altı adet çıktı katmanı düğümüne tam bağlantılı şekilde yapılandırılmış ve çıktı katmanında aktivasyon fonksiyonu (ve aynı zamanda da çoklu sınıflandırma fonksiyonu) olarak Softmax kullanılmıştır. Evrişimsel sinir ağ1 modelimiz; çıktı katmanında yer alan altı düğümün her birinin altı farklı mermer sinıfindan birisini temsil edecek şekilde yapılandırılmıştır. Evrişimsel sinir ağı modelimizin eğitim sürecinde, yığın normalleştirmesinde her bir yığının boyutu 16 olarak ayarlanmış ve eğitim toplam 30 devir (epoch) boyunca sürdürülmüştür. Öğrenme hızının ayarlanmasında uyumsal öğrenme hızı optimizasyonu modellerinden birisi olan Adam algoritması kullanılmış [15, 16] ve ilk öğrenme hızı 0,001 olarak tanımlanmıştır.

Evrişimsel sinir ağı modelimiz, Python programlama dilinin 3.6.7 sürümü ve şu yazılım mimarileri ve kütüphaneleri kullanılarak kodlanmıştır: Keras 2.2.4, Tensorflow 1.13.1, PyCharm Pro. 2018.1.4 ve Atom 1.34.0. Kodumuzun bazı kısımları Şekil 5 ve Şekil 6'da gösterilmektedir. Bu çalışmadaki deneylerimiz ve testlerimizde ilk başta $300 \mathrm{x}$ 352
300 piksel boyutlarındaki renkli mermer görselleri kullanılmıştır. Birçok farklı evrişimsel sinir ağı modeli ve çok farklı hiper-parametrelerle deneyler yapıldı ̆̆ 1 halde, istenilen doğruluk oranları elde edilememiş, özellikle eğitim (train) sonunda altı sınıfın doğruluk oranı 1,0' e ulaşsa bile, geçerleme ve testlerde aşırı düşüşler gözlenmiş ve aşırı uyum (overfitting) sorunu gözlenmiştir. Evrişimsel sinir ağ1 modelimizdeki yığın normalleştirmesi aşamasında farklı yı̆̆ın boyutları denenmiş, ayrıca seyreltme oranları da değiştirilerek birçok farklı deney yapılmıştır. Fakat tüm bu farklı yaklaşımlarda aşırı uyum sorunu aşılamamıştır. Öte yandan, aynı mermer verileri diğer alternatif yapay öğrenme algoritmalarıyla denendiğinde de aşırı uyum sorunu sürekli olarak gözlemlenmiştir.

Test ve geçerleme sonuçlarının doğruluk oranını arttırmak ve aşırı uyum sorununu gidermek amacıyla; çalışmamızda çeşitli veri artırımı yöntemlerinin denenmesine karar verilmiştir. Öncelikle L1 ve L2 regülasyonları denenmiş [15, 16], ancak bu yöntemlerin modelimizdeki aşırı uyum sorununu gidermediği gözlemlenmiştir. Ayrıca, evrişimsel sinir ağlarında aşırı uyumu gidermede diğer bir strateji olan veri artırımı ve buna bağlı olarak görsel verilerde sıklıkla kullanılan gürültü ekleme (noise injection), görüntü döndürme (image rotation), renk seğirmesi (color jittering), görüntüyü yatay ve düşey döndürme (horizontal and vertical flips) ve rastgele kırpma (random cropping) gibi çeşitli görüntü işleme teknikleri de denenmiştir $[15,22]$. Buna ek olarak; Gabor filtresi, iki taraflı filtreleme (bilateral filter), medyan filtresi, Retinex, Msrcp ve Automated-Retinex gibi bazı özel görüntü işleme yöntem ve filtreleri de mermer 


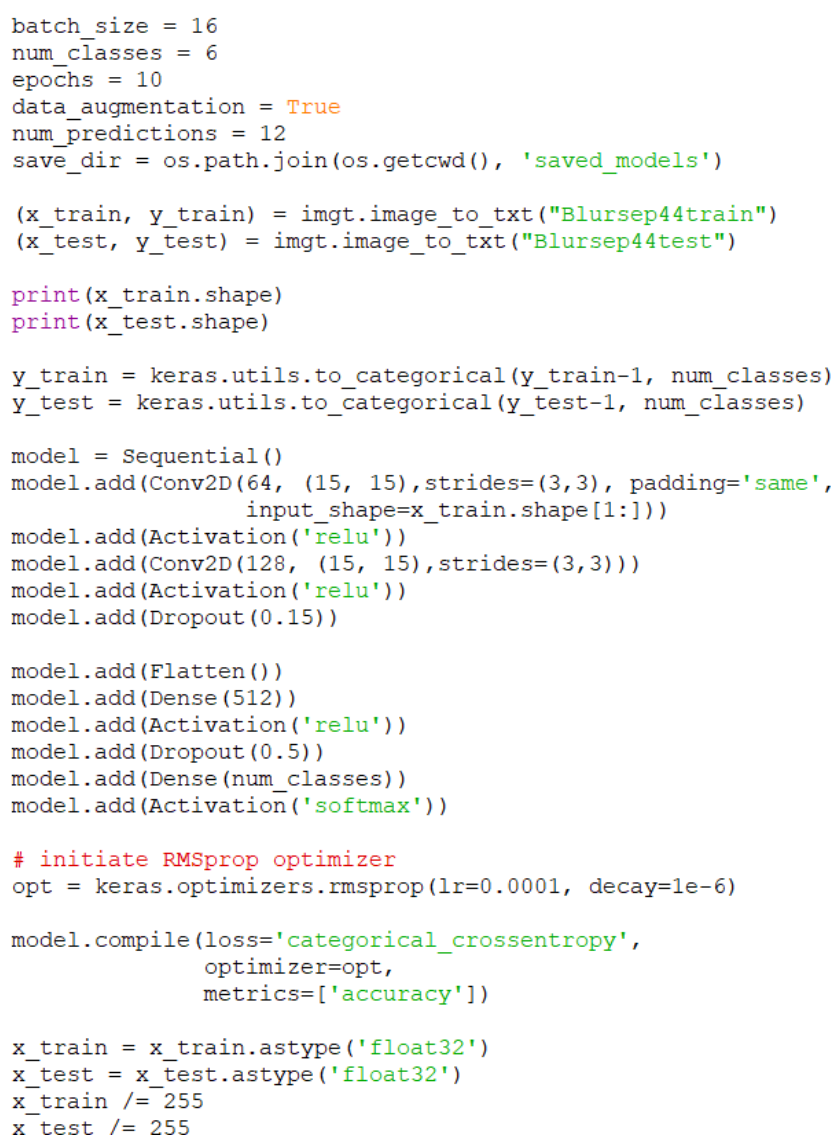

Şekil 5. Evrişimsel sinir ağımızın mimarisi ve parametrelerinin tanımlandığı Python kod parçası (Python code for the architecture and parameter settings of our convolutional neural network model)

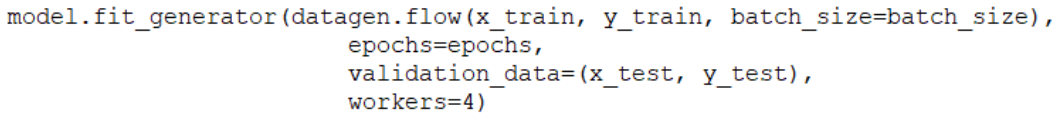

Şekil 6. Eğitim sonundaki modelin ve elde edilen test sonuçlarının kayıtlandığı Python kod parçası (Python code for saving the trained model and printing the test results)

görselleri üzerinde kullanılmıştır [23]. Her bir farklı yöntem, mermer görsellerinin tamamında uygulanıp; oluşan yeni görseller de, veri setine dâhil edilmiş ve sonrasında da evrişimsel sinir ağında yeni baştan eğitim ve testleri yapılmıştır. Fakat bunların hiçbiri aşırı uyum sorununu çözememiş ve özellikle testlerdeki doğruluk oranlarını iyileştirememiştir. Tüm bu başarısız sonuçlardan sonra, aşırı uyum sorununu giderebilmek amaciyla daha özgün bir yaklaşım denenmesine karar verilmiş, seçilen bazı görüntü işleme filtreleri mermer görselleri üzerinde uygulanarak yeni görseller elde edilmiştir. Farklı görüntü işleme yöntem ve filtrelerinin görseller üzerinde uygulanmasında da, 82 farklı model belirlenip denenmiş ve her birisi ayrı ayrı evrişimsel sinir ağında çalıştırılmıştır. En sonunda, mermer levha görselleri ve evrişimsel sinir ağı için aşırı uyum sorununu da aşacak şekilde, olabilecek en yüksek doğruluk oranını elde eden görüntü işleme ve veri artırımı yaklaşımı ortaya konulmuştur. Veri setindeki her bir mermer görseline; bulanıklaştırma filtresi (blur filter) ve iki boyutlu doğrusal ayrıştırıcı filtre (2D Linear Separable Filter) uygulanarak yeni görsel örnekleri elde edilmiş ve bunlar da veri setine eklenmiştir. 


\section{SONUÇLAR VE TARTIŞMALAR (RESULTS AND DISCUSSIONS)}

Görüntü bulanıklaştırması, 4 x 4' lük matristen oluşan bir düşük geçişli (low-pass) filtreyle [24] mermer görsellerinin evriştirilmesi yoluyla sağlanmış olup bu sayede mermer resimlerindeki gürültü ve bozunumlar temizlenebilmiştir. Bu çalışmada kullanılan mermer görsellerinin pek çok oyuk (pit) damar (vein) ve fosil kalıntısı içermesinden dolayı, bulanıklaştırma filtresi sayesinde daha pürüzsüz görseller elde edilmesi sağlanmıştır. Öte yandan, bulanıklaştırma filtresinin tek başına kullanılması, oyuk ve damarların ayırt edilebilir hale getirilmesinde yeterli olmamıştır. Mermer görsellerindeki damar desenlerini daha iyi ayırt edilebilir hale getirmek amacıyla da, iki boyutlu doğrusal ayrıştırıcı filtre kullanılmıştır [24].

Görsellere ayrı ayrı uygulanan bu filtreleme işlemleri ile elde edilen yeni görseller, mevcuttaki veri setine eklenerek veri artırımı sağlanmıştır. Bu sayede, çalışmamızdaki veri setinde bulunan görsel örneklerin adedi 6300' e yükselmiştir. Alt1 farklı mermer kalitesi sınıfının her birine ait olan örnek sayısı 1050 ' dir. Bu veri setindeki görsellerin 5400 adedi eğitim için ve 900 adedi de test için ayrılıp kullanılmıştır. Buna ek olarak, 6300 örneğin tamamı 10 katlı çapraz geçerlilik yöntemiyle yapılan deneylerde kullanılmıştır.

Bu çalışmada ortaya konan evrişimsel sinir ağı modeli, diğer bazı bilinen yapay öğrenme algoritmalarıyla karşılaştırmalı olarak analiz edilerek, her birisi ile elde edilen ortalama doğruluk oranları Tablo 1 ve Tablo 2'de sunulmuştur. Çalışmada kapsama alınan yapay öğrenme algoritmaları içerisinde, özellikle ilgili literatürde görsel verilerin çoklu sınıflandırması amacıyla kullanılanlar; çok katmanlı algılayıcı, k en yakın komşu, C4.5 ve Naive Bayes olarak sıralanabilir. Çok katmanlı algılayıcı (multilayer perceptron), ileri beslemeli bir yapay sinir ağ 1 modelidir ve kademeli iniş ve geri yayılım ile hataların hesaplanması ve ağırlık güncellemelerini yapmaktadır. Çoğunlukla bir ya da bir kaç gizli katmandan oluşur ve genellikle çıktı aktivasyon fonksiyonu olarak Sigmoid tercih edilir. Öğrenme hızı, momentum, tekrar sayısı ve gizli katmanlardaki düğüm sayısı esnek bir şekilde değiştirilebilir [16]. k en yakın komşu (k-nearest neighbors ya da $\mathrm{k}-\mathrm{NN}$ ); veri setindeki kayıtlar arasındaki benzerlik ya da uzaklığa bağlı olarak ögrenen ve her bir kayd, hiper uzaydaki bir vektör olarak tanımlayan bir yapay öğrenme algoritmasıdır $[25,26]$. Naive Bayes; sınıflandırma problemleri için kullanılan ve Bayes teoremine dayanan bir algoritma olup öz niteliklerin birbirinden tamamen bağımsız olduğunu varsayar [27, 28]. C4.5; sınıflandırma problemleri için kullanılan ve bilgi kazanımı yöntemini kullanarak ağacın gövde, yaprak ve dallarını oluşturan bir karar ağacı algoritmasıdır [27].

Tablo 1'deki sonuçlar orijinal mermer görselleri kullanılarak elde edilmiş olup bu örneklerden 1800' ü eğitim ve 300'ü test için ayrılarak analiz edilmiş; ayrıca 2100 örneğin tamamıyla on katlı çapraz geçerleme yapılmıştır. Tablo 1'de de görülebileceği gibi, orijinal mermer görsellerinden elde edilen sonuçlar; test ve geçerlemede gözlenen oldukça düşük doğruluk oranları yanı sıra, aşırı uyum sorunundan ötürü tatmin edici değildir. Öte yandan, özgün görüntü işleme yaklaşımımız sonucundaki veri artırımı sayesinde toplam 6300 görselden oluşan veri seti ile çok daha başarılı sonuçlar elde edilmiş olup bu sonuçlar Tablo 2'de gösterilmektedir.

Tablo 1 ile karşılaştırıldığında; Tablo 2'de evrişimsel sinir ağı modelimiz yanı sıra diğer tüm alternatif algoritmaların da doğruluk oranlarının kayda değer biçimde yükseldiği görülmektedir. Ayrıca, Tablo 2 incelendiğinde evrişimsel sinir ağı modelimizin; hem test sonuçlarında, hem de çapraz geçerleme sonuçlarında diğer tüm algoritmalardan çok daha yüksek başarı oranları sağladığı ve aşırı uyum sorununun yüksek düzeyde olmadığı görülmektedir. Tablo 2'de de görüleceği şekilde, evrişimsel sinir ağı modeli ile test

Tablo 1. Evrişimsel sinir ağı modelimizle çeşitli yapay öğrenme algoritmalarının 2100 adet resimden oluşan orijinal veri seti ile elde edilen sonuçlarının karşılaştırması

(Performance comparison of several classifier algorithms versus our CNN model using the original dataset with 2100 images)

\begin{tabular}{lccc}
\hline Algoritma adı ve parametre değerleri & $\begin{array}{c}\text { Ortalama } \\
\text { doğruluk } \\
\text { oranı (Ĕ̆itim) }\end{array}$ & $\begin{array}{c}\text { Ortalama } \\
\text { doğruluk } \\
\text { oranı (Test) }\end{array}$ & $\begin{array}{c}\text { Ortalama doğruluk } \\
\text { oranı } \\
\text { (10 katlı çapraz } \\
\text { geçerleme) }\end{array}$ \\
\hline $\begin{array}{l}\text { Evrişimsel sinir ă̆ı modeli } \\
\text { k-NN (k en yakın komşu k=1, Öklid uzaklı̆̆1) }\end{array}$ & 1.000 & 0.714 & 0.701 \\
$\begin{array}{l}\text { Çok katmanlı algılayıcı (64 düğümlü bir adet } \\
\text { gizli katman, öğrenme hızı=0.1, momentum=0.2, } \\
\text { aktivasyon fonksiyonu: sigmoid) }\end{array}$ & 0.915 & 0.652 & 0.661 \\
$\begin{array}{l}\text { Çok katmanlı algıllayıcı (256 ve 128 adet } \\
\text { düğümlü iki adet gizli katman, öğrenme } \\
\text { h1zı=0.03, momentum=0.1, aktivasyon } \\
\text { fonksiyonu: sigmoid) }\end{array}$ & & 0.695 & 0.697 \\
$\begin{array}{l}\text { C4.5 Karar Ağacı } \\
\text { Naïve Bayes }\end{array}$ & 0.910 & 0.701 & 0.693 \\
\hline
\end{tabular}


Tablo 2. Evrişimsel sinir ağı modelimizle çeşitli yapay öğrenme algoritmalarının veri artırımı sonrası 6300 adet resimden oluşan veri seti ile elde edilen sonuçlarının karşılaştırması

(Performance comparison of several classifier algorithms versus our CNN model using the augmented dataset with 6300 images)

\begin{tabular}{|c|c|c|c|}
\hline Algoritma adı ve parametre değerleri & $\begin{array}{c}\text { Ortalama } \\
\text { doğruluk } \\
\text { oranı (Eğitim) }\end{array}$ & $\begin{array}{l}\text { Ortalama } \\
\text { doğruluk } \\
\text { oran1 (Test) }\end{array}$ & $\begin{array}{c}\text { Ortalama doğruluk } \\
\text { oranı } \\
\text { (10 katlı çapraz } \\
\text { geçerleme) }\end{array}$ \\
\hline Evrişimsel sinir ă̆l modeli & 1.000 & 0.922 & 0.961 \\
\hline k-NN (k en yakın komşu k=1, Öklid uzaklığı) & 0.906 & 0.729 & 0.703 \\
\hline $\begin{array}{l}\text { Çok katmanlı algılayıcı ( } 64 \text { düğümlü bir adet } \\
\text { gizli katman, öğrenme hızı }=0.1, \text { momentum }=0.2 \text {, } \\
\text { aktivasyon fonksiyonu: sigmoid) }\end{array}$ & 0.893 & 0.748 & 0.757 \\
\hline $\begin{array}{l}\text { Çok katmanlı algılayıcı ( } 256 \text { ve } 128 \text { adet } \\
\text { düğ̈̈mlü iki adet gizli katman, ögrrenme } \\
\text { hızı=0.03, momentum }=0.1 \text {, aktivasyon } \\
\text { fonksiyonu: sigmoid) }\end{array}$ & 0.917 & 0.705 & 0.712 \\
\hline C4.5 Karar Ağacı & 0.821 & 0.694 & 0.685 \\
\hline Naïve Bayes & 0.735 & 0.655 & 0.661 \\
\hline
\end{tabular}

sonucunda elde edilen ortalama doğruluk oranı 0,922 olup, ikinci en iyi sonucu veren çok katmanlı algılayıcı (MLP) tipindeki yapay sinir ağı ile elde edilen ortalama doğruluk oranı ise sadece 0,748' dir. Benzer şekilde, evrişimsel sinir ağı modeli ile on katlı çapraz geçerleme sonucunda ortalama doğruluk oranı 0,961 olarak gözlemlenmiş, ikinci en başarılı sonucu veren çok katmanlı algılayıcı tipindeki yapay sinir ağının ortalama doğruluk oranı ise sadece 0,757 olarak ele edilmiştir.

Bianconi vd'nin çalışmasında [3], oldukça zor ayırt edilebilen mermer görsellerinden farklı olarak, granit görselleri kullanılmış ve granit sınıflaması yapılmıştır. Granitlerin oluşumu mermerlere göre daha uzun y1llar almakta ve bu nedenle granitler daha fazla kristalize madde içermektedir. Granitlerde genelde öbek şeklinde bozulmalar gözlemlenir fakat mermerlerde damarlar, fosiller ve ya delikler oluşabilmektedir. İlgili makalede de gösterildiği şekilde, farklı granit sınıflarının her birisinin diğerinden ayırt edilebilirliği bizim çalışmadaki mermer örneklerine göre daha kolaydır. Doğan ve Akay [8] ile Selver ve arkadaşlarının [9] çalışmalarında ise, Manisa bölgesindeki kireçtaşı örnekleri kullanılmıştır. Kimyasal yapısı birbirine çok benzese de, kireçtaşı ile mermer arasındaki kökeni ve sahip oldukları fiziksel özellikler açısından birçok farklılıklar vardır. Mermer, kireçtaşına kıyasla renk çeşitliliğine sahiptir ve hem uzmanlar, hem de bilgisayar otomasyon sistemleri için farklı kalitelere ait mermerlerin ayırt edilmesi kireçtaşlarına göre daha zordur.

\section{SONUÇLAR (CONCLUSIONS)}

$\mathrm{Bu}$ çalışmada; mermer levhalarının görselleri kullanılarak mermer kalitesinin sinıflandırılmasında yeni bir model ve yaklaşım ortaya konulmuştur. Çalışmamızın orijinalliği ve ilgili literatüre olan katkısı; mermer kalitesinin çoklu sınıflandırılmasında özel olarak tasarlanmış bir evrişimsel sinir ağ1 modelinin kullanılması, iki farklı görüntü işleme yönteminin (bulanıklaştırma filtresi ve iki boyutlu doğrusal ayrıştırıcı filtre) veri artırımı amacıyla aşırı uyum sorununu da giderecek şekilde kullanılması ve altı farklı kalite sınıfına ait verilerin oldukça zor olan sınıflandırma işleminin çok yüksek doğruluk oranlarıyla elde edilmesi olarak özetlenebilir. Çalışmamızda geliştirilmiş olan evrişimsel sinir ağı modeli ve veri artırımı yöntemleri sayesinde elde edilen doğruluk oranları, diğer yapay öğrenme algoritmaları kullanılarak elde edilen oranlardan çok daha yüksek olmuştur. Buna ek olarak; Haz Mermer Sanayi ve Ticaret A.Ş.'nin kalite kontrol uzmanları ve yöneticileri, evrişimsel sinir ağ1 modeli ile elde edilen doğruluk oranlarının, eksperlerin manuel olarak yaptığı mermer kalite sınıflandırmasına çok yakın düzeyde olduğunu belirtmiştir. Mermer kalite kontrol sınıflandırması için spesifik bir ulusal ya da uluslararası standart (ISO, TSE, vb) henüz yürürlükte olmadığından, mermer sektöründe kalite kontrol ve ilgili diğer süreçler bu konudaki uzman yorumları ile yapılmaktadır. $\mathrm{Bu}$ nedenle, çalışmamızda elde ettiğimiz sonuçlar, mermer görsellerini edindiğimiz Haz Mermer Sanayi ve Ticaret A. Ş.'nin mermer kalite kontrol uzmanlarınca değerlendirilmiştir. $\mathrm{Bu}$ çalışmada ortaya konulan modelin; mermer fabrikaları ve işletmelerinde insanlar tarafindan gerçekleştirilen manuel kalite kontrol ve kalite sınıflandırması süreçlerinin yerini alacak şekilde, bilişim sistemleri ile otomatikleştirilmiş bir biçimde kullanılabilecek bir alternatif olabileceği düşünülebilir. Günümüzde ülkemiz de dâhil olmak üzere dünyanın birçok ülkesinde Endüstri 4.0 çözümleri ve uygulamalarının çok etkili ve hızlı biçimde yayıldığı gerçeği göz önüne alındığında, ortaya konan modelimizin bu açıdan da bir katkısı ve önemi bulunmaktadır.

Yakın gelecekte planladığımız çalışmalardan biri de; mermer işletmelerindeki endüstriyel uygulamalar için bu çalışmadaki yöntem ve modeli bir bilişim ürünü ve 
uygulama paketi olarak ortaya koymaktır. Önceden eğitilmiş (pre-trained) evrişimsel sinir ağı modelimiz ve veri artırımı amacıyla kullanılan görüntü ön-işleme sürecimiz; kameralı elektronik aygitlar veya akıllı telefonlar üzerinde çalıştırılabilecek tek bir yazılım paketine ya da tek bir uygulama içerisine yerleştirilebilir. $\mathrm{Bu}$ aygıtlar, mermer işleme tezgâhlarındaki uygun noktalara yerleştirilerek insan müdahalesi olmaksızın her bir yeni mermer levhasının fotoğrafını çekerek mermeri doğru kalite sınıfına atayabilecektir. Bu sistemde, mermer görselleri için önceden eğitilmiş bir evrişimsel sinir ağ modeli kullanılmış olduğundan, eğitim aşaması için herhangi bir bekleme süresi olmayacağı; bununla birlikte canlı sistemdeki görüntü önişleme süreçleri için belli bir çalıșma süresi gereksiniminin ortaya çıkacağı dikkate alınmalıdır. $\mathrm{Bu}$ nedenle; otomatikleştirilmiş mermer kalite sınıflandırma işleminin, gerçek zamanlı sistemler ve endüstriyel uygulamalarda kabul edilebilir bir sürede çalıştırılabilmesi için görüntü önişleme aşamasının yüksek düzeyde etkili ve hızlı algoritmalar ve teknolojiler kullanılarak gerçekleştirilmesi gerekmektedir.

\section{TEŞEKKÜR (ACKNOWLEDGEMENT)}

Makalenin yazarları; bu çalışmada mermer levha görsellerini sağlayan ve değerli geri bildirimlerde bulunan Haz Mermer Sanayi ve Ticaret A.Ş. yöneticileri ve uzmanlarına teşekkürlerini sunar.

\section{KAYNAKLAR (REFERENCES)}

1. Karaca, Z., Quality control of marble blocks, MERSEM 2003 IV. Marble Symposium, Afyon-Türkiye, 497-503, 18-19 Aralık, 2003.

2. Yavuz, A.B., Türk, N., Koca, M.Y., The use of micritic limestone as building stone: A case study of Akhisar beige marble in western Turkey, IMBS 2003 International Symposium of Industrial Minerals and Building Stones, İstanbul-Türkiye, 277-281, 15-18 Eylül, 2003.

3. Bianconi, F. et al, Automatic classification of granite tiles through colour and texture features, Expert Systems with Applications, 39 (12), 11212-11218, 2012.

4. Selver, M.A. et al, An automated industrial conveyor belt system using image processing and hierarchical clustering for classifying marble slabs, Robotics and Computer-Integrated Manufacturing, 27 (1), 164-176, 2011.

5. Unser, M., Sum and difference histograms for texture classification, IEEE Transactions on Pattern Analysis and Machine Intelligence, 8 (1), 118-125, 1986.

6. Martinez-Alajarin, J., Luis-Delgado, J.D., TomasBalibrea, L.M., Automatic system for quality based classification of marble textures, IEEE Transactions on Systems, Man, and Cybernetics, Part C, 35 (4), 488497, 2005.

7. Martinez-Alajarin, J., Luis-Delgado, J.D., TomasBalibrea, L.M., Classification of marble surfaces using wavelets, Electronics Letters, 39 (9), 714-715, 2003.
8. Doğan, H. ve Akay, O., Using AdaBoost classifiers in a hierarchical framework for classifying surface images of marble slabs, Expert Systems with Applications, 37 (12), 8814-8821, 2010.

9. Selver, M.A. et al, Cascaded and hierarchical neural networks for classifying surface images of marble slabs, IEEE Transactions on Systems, Man, and Cybernetics, Part C, 39 (4), 426-439, 2009.

10. Ferreira, A. ve Giraldi, G., Convolutional Neural Network approaches to granite tiles classification, Expert Systems with Applications, 84, 1-11, 2017.

11. Bianconi, F. et al, On comparing colour spaces from a performance perspective: Application to automated classification of polished natural stones, New Trends in Image Analysis and Processing, 9281, 71-78, 2015.

12. The MNIST Database of handwritten digits. http://yann.lecun.com/exdb/mnist/. Yayın tarihi 2001. Erişim tarihi Kasım 8, 2019.

13. The CIFAR-10 dataset. https://www.cs.toronto.edu/ kriz/cifar.html. Yayın tarihi 2009. Erişim tarihi Eylül 21, 2019.

14. Pençe, İ. ve Çeşmeli, M.Ş., Deep Learning in Marble Slabs Classification, Techno-Science, 2 (1), 21-26, 2019.

15. Goodfellow, I., Bengio, Y., Courville, A., Deep Learning, MIT Press, Cambridge, MA, A.B.D., 2016.

16. Buduma, N. ve Locascio, N., Fundamentals of Deep Learning: Designing Next-Generation Machine Intelligence Algorithms, O’ Reilly, A.B.D., 2017.

17. Yildiz O., Melanoma detection from dermoscopy images with deep learning methods: A comprehensive study, Journal of the Faculty of Engineering and Architecture of Gazi University, 34 (4), 2241-2260, 2019.

18. LeCun, Y. et al, Backpropagation applied to handwritten zip code recognition, Neural Comp., 1, 541-551, 1989.

19. Hanbay K., Hyperspectral image classification using convolutional neural network and two dimensional complex Gabor transform, Journal of the Faculty of Engineering and Architecture of Gazi University, 35 (1), 443-456, 2020.

20. Ar1 A., Hanbay D., Tumor detection in MR images of regional convolutional neural networks, Journal of the Faculty of Engineering and Architecture of Gazi University, 34 (3), 1395-1408, 2019.

21. Hahnloser, R. et al, Digital selection and analogue amplification coexist in a cortex-inspired silicon circuit, Nature, 405, 947-951, 2000.

22. Avc1 K., Two dimensional digital filter design using Kaiser-Hamming window structure and Huang transform and image enhancement application, Journal of the Faculty of Engineering and Architecture of Gazi University, 33 (4), 1459-1474, 2018.

23. Filters. https://github.com/realka/DataPreparation. Yayın tarihi Temmuz 18, 2018. Erişim tarihi Mayıs 17, 2019.

24. Image Filtering. https://docs.opencv.org/2.4/modules/imgproc/doc/filter ing.html. Yayın tarihi 2011. Erişim tarihi Nisan 22, 2019. 
25. Aha, D.W., Kibler, D., Albert, M.K., Instance-based learning algorithms, Machine Learning, 6 (1), 37-66, 1991.

26. Küçük H., Eminoğlu İ., Balcı K., Classification of neuromuscular diseases with artificial intelligence methods, Journal of the Faculty of Engineering and Architecture of Gazi University, 34 (4), 1725-1742, 2019.
27. Han, J., Pei, J., Kamber, M., Data mining: concepts and techniques, Elsevier, Waltham, MA, A.B.D., 2011.

28. Utku A., Doğru İ., Permission based detection system for android malware, Journal of the Faculty of Engineering and Architecture of Gazi University, 32 (4), 1015-1024, 2017. 
